\title{
L-Arginine:glycine amidinotransferase deficiency
}

INSERM

\section{Source}

INSERM. (1999). Orphanet: an online rare disease and orphan drug data base. $\underline{\text { L- }}$ Arginine:glycine amidinotransferase deficiency. ORPHA:35704

L-Arginine:glycine amidinotransferase (AGAT) deficiency is a very rare type of creatine deficiency sydrome characterized by global developmental delay, intellectual disability, and myopathy. 